\title{
PERCEPÇÕES SOBRE A FORMAĈ̃O DE PROFESSORES DE CIÊNCIAS VOLTADAS A EDUCAÇÃO AMBIENTAL: COM A PALAVRA OS EGRESSOS DO CURSO DE CIÊNCIAS NATURAIS
}

\author{
Manolo Cleiton Costa Freitas 1 \\ Silvio Carlos Ferreira Pereira Filho ${ }^{2}$ \\ Ana Carolina Gomes de Albuquerque de Freitas ${ }^{3}$
}

Resumo: Este trabalho é resultado de uma pesquisa desenvolvida com egressos do curso de Licenciatura em Ciências Naturais de uma universidade pública e teve como objetivo principal investigar de que forma as disciplinas ofertadas durante a formação acadêmica contribuíram para a formação do professor como educador socioambiental e, como objetivo secundário, melhorar a formação de professores, contribuir com a gestão de ensino e facilitar a inserção da Educação Ambiental (EA) nas futuras práticas docente de egressos do curso de uma Instituição de Ensino Superior. Para tal, foram consideradas as percepções dos egressos quanto ao conteúdo, práticas dos docentes e aprendizagem dos sujeitos da pesquisa. Para a realização desta pesquisa, foram adotados os procedimentos metodológicos de uma abordagem qualiquantitativa, utilizando formulário eletrônico constituído por perguntas abertas e fechadas. A maioria das perguntas fechadas foram formuladas seguindo a escala Likert de concordância e os resultados apresentados em gráficos. Para a interpretação das respostas abertas foi utilizado a análise de conteúdo segundo Flick (2013). O estudo revela as percepções dos egressos quanto a sua satisfação com a formação ofertada, investiga os pontos fortes e fracos da formação voltada à $E A$, além de possibilitar oportunidades de reflexão crítica para melhorar a formação de professores de ciências com um olhar mais sensível à EA.

Palavras-chave: Percepção de Egressos; Educação Ambiental; Formação de Professores.

1 Universidade Federal do Pará. E-mail: manolo@ufpa.br

2 Universidade Federal do Pará. E-mail: silviocfilho@ufpa.br

${ }^{3}$ Universidade Federal do Pará. E-mail: albuquerqueacg@gmail.com 
Abstract: This work is the result of a research developed with graduates of the Natural Sciences Degree course at a public university whose main objective was to investigate how the subjects offered during academic training contributed to the formation of the teacher as a socioenvironmental educator and, as an objective secondary education, improve the training of teachers, contribute to teaching management and facilitate the insertion of Environmental Education (EE) in the future teaching practices of graduates of a Higher Education Institution. To this end, the perceptions of the graduates regarding the content, practices of teachers and learning of the research subjects were considered. To carry out this research, the methodological procedures of a qualiquantitative approach were adopted, using an electronic form consisting of open and closed questions. Most closed questions were asked using the Likert scale of agreement and the results presented in graphs. For the interpretation of open responses, content analysis was used according to Flick (2013). The study reveals the graduates' perceptions of their satisfaction with the training offered, investigates the strengths and weaknesses of training aimed at EE, in addition to providing opportunities for critical reflection to improve the training of science teachers with a more sensitive view to EE,

Keywords: Perception of Graduates; Environmental Education; Teacher Training.

\section{Introdução}

\section{Ensino sobre a Educação Ambiental}

Desde o final da década de 1960, os problemas ambientais decorrentes das ações humanas têm gerado preocupações quanto ao futuro do planeta $\mathrm{e}$ isso vem exigindo que toda a sociedade repense sobre esses problemas. Isso levou a necessidade de se instituir uma Educação Ambiental (EA) que busque, dentre muitas coisas, gerar mudanças de pensamentos, percepções, comportamentos e atitudes do indivíduo quanto à questão ambiental.

A escola é considerada como um dos principais espaços para o desenvolvimento da EA. Como afirmam Silva e Leite (2008) que:

A realização de Educação Ambiental tendo início na escola, poderá atingir os demais segmentos da sociedade, já que a inserção da dimensão ambiental na escola proporciona a realização de um trabalho contínuo e permanente e as transformações alcançadas, transpõem os muros da mesma (SILVA; LEITE, p. 376, 2008 apud SILVA, 1995)

Assim, se a EA for feita de forma eficaz na escola, poderá ter reflexos na sociedade que venham a ser determinantes na mudança do curso atual que estamos traçando como civilização.

Desse modo, a EA deve ser realizada de forma a trazer mudanças à sociedade. Para isso, uma das abordagens que devem ser realizadas é desenvolver a EA como uma prática em todos os lugares que educam o cidadão, sejam eles formais ou informais. 
No Brasil, existem leis que determinam a inserção da EA no ensino formal, como exemplo, a Política Nacional de Educação Ambiental (Lei 9.795/99) que trata da obrigatoriedade de existir EA em todos os níveis de ensino (BRASIL, 1999). Além dessa, a Lei de Diretrizes e Bases da Educação Brasileira (Lei 9.394/96) determina que a EA deva ser desenvolvida nas escolas através de atividades que trabalhem interdisciplinarmente a percepção ambiental dos estudantes. Por sua vez, os Parâmetros Curriculares Nacionais (PCN) orientam que o tema meio ambiente deva ser abordado de maneira transversal e mostram também que é necessário que os educadores trabalhem interdisciplinarmente as questões ambientais em suas aulas. Assim, no ensino formal, a EA deve ser trabalhada em uma perspectiva interdisciplinar e não como uma disciplina, em um processo que permita que o tema meio ambiente permeie todos os conteúdos ministrados.

Um dos princípios gerais de qualquer processo educativo para uma aprendizagem mais significativa é o descrito por David Ausubel et al. (1978):

A aprendizagem significativa acontece quando uma informação nova é adquirida mediante um esforço deliberado por parte do aprendiz em ligar a informação nova com conceitos ou proposições relevantes preexistentes em sua estrutura cognitiva (AUSUBEL et al., 1978, p. 159).

No entanto, muitas vezes não é óbvio para o aluno quais ligações ele pode fazer entre o conhecimento novo e o preexistente, sendo necessário que o professor torne estas ligações mais óbvias. Para isso, é necessário que o professor tenha uma ideia de quais são estes conhecimentos preexistentes na estrutura cognitiva do estudante. Especificamente para a EA, os conhecimentos preexistentes dos alunos à respeito de meio ambiente também são conhecidos como percepção ambiental.

Silva e Leite (2008, p.374) consideram que o conhecimento sobre a percepção ambiental do estudante é importante porque

a degradação ambiental decorre, dentre outros aspectos da forma como percebemos o meio ambiente. A ausência, inadequação ou escassez do conhecimento gera ações que em geral, estão em desacordo com as leis naturais.

Revbea, São Paulo, V. 16, № 6: 414-435, 2021. 
sensibilização do indivíduo sobre a sua realidade, para que assim ocorram nele mudanças de valores, comportamentos e atitudes no meio em que está inserido.

Para além da percepção dos alunos sobre meio-ambiente, é importante conhecer também as concepções que têm os professores para entender como a EA tem sido trabalhada em suas práticas pedagógicas. Isso é relevante para compreender os problemas existentes no ensino brasileiro no que diz respeito ao desenvolvimento da EA nas escolas. Infelizmente, as percepções sobre o meio ambiente apresentadas por professores, inclusive os de ciências, são visões, ao mesmo tempo, simplistas, naturalistas e utilitaristas (Camargo e Branco, 2003). Essas concepções dos educadores limitam-se, por exemplo, a perceberem o meio ambiente como apenas um lugar para viver e desconsideram os fatores culturais, econômicos e sociais como integrantes desse meio. Esse é um dos fatores que torna a EA deficiente no sistema educacional, pois os professores apresentam uma percepção superficial sobre o meio ambiente, além de não estarem sensibilizados para trabalhar a conscientização dos alunos em sala de aula.

A universidade como formadora de professores tem a responsabilidade de inserir a dimensão ambiental nos currículos dos cursos de licenciatura (Abreu et al., 2008). É importante que o professor tenha experiências com a EA na licenciatura para que, assim, este profissional não continue com uma percepção limitada sobre o meio ambiente e, consequentemente, leve essa visão para a sala de aula. Para além disso, Silva e Leite (2008, p. 382) afirmam que:

A formação voltada para o meio ambiente de educadores e educadoras é a principal estratégia em Educação Ambiental, tanto na formação inicial como na continuada. Não será possível obter mudanças em vários aspectos, sem que os educadores e educadoras possam estar sensibilizados e em condições de executar o seu papel na educação e na sociedade. Não podemos exigir destes profissionais, formação na área ambiental, se estes não a recebem nos cursos de licenciaturas.

Entretanto, a inserção da EA não ocorre de forma efetiva no ensino superior, sendo essa mais trabalhada na educação básica. Pois, não é incomum nos deparamos com Projetos Pedagógicos de Cursos em nível superior carentes ou, em alguns casos, em descumprimento ao estabelecido no Art. 12 da Resolução $\mathrm{N}^{\circ} 2$, de $1^{\circ}$ de julho de 2015, do Ministério da Educação (Brasil, 2015), devido, principalmente, a terem sidos criados antes da publicação da referida resolução e não terem sido readequados posteriormente. Isso, de qualquer forma, é preocupante, pois é indispensável que os professores, na sua formação inicial ou continuada, tenham o preparo necessário para trabalharem as questões ambientais e olhem o meio ambiente 
de forma mais ampla, para assim desenvolverem atividades de EA possíveis de gerar transformações nos alunos que beneficiem o meio ambiente.

$\mathrm{Na}$ educação básica é comum observar que a EA é abordada através de aulas de campo, projetos, mutirões, atividades em datas especiais, palestras, debates, aulas expositivas, entre outros (CAMARGO; BRANCO, 2003; ABREU et al., 2008; SILVA; LEITE, 2008). Para que a EA seja de fato um instrumento de mudança, é importante que ela seja trabalhada de forma interdisciplinar através de várias estratégias de ensino para que, assim, questões ambientais sejam tratadas de forma interativa/atrativa, não se restringindo a aulas expositivas, e despertem nos alunos a responsabilidade individual com relação ao meio ambiente.

Para realização das atividades de $E A$ é necessário que a responsabilidade não seja atrelada exclusivamente à formação que o professor recebeu. Abreu et al. (2008, p. 692) afirma que "é imprescindível que as escolas ofereçam infraestrutura e apoio administrativo para realização das atividades". É muito importante que ocorra essa integração para que a EA possa ser desenvolvida, pois não é responsabilidade apenas do educador fazêla, mas que todo o sistema educacional esteja comprometido em efetivá-la.

Portanto, a EA é considerada necessária para a resolução dos problemas ambientais existentes, sendo utilizada como estabelece seus objetivos na Lei 9.795/99 (BRASIL 1999, s.p.):

[...] I - o desenvolvimento de uma compreensão integrada do meio ambiente em suas múltiplas e complexas relações, envolvendo aspectos ecológicos, psicológicos, legais, políticos, sociais, econômicos, científicos, culturais e éticos; II - a garantia de democratização das informações ambientais; III - o estímulo e o fortalecimento de uma consciência crítica sobre a problemática ambiental e social; [...]

Assim, os processos envolvendo a EA auxiliam nas mudanças de concepções, valores, atitudes e comportamentos do indivíduo, e que devem ser postas em prática em todos os lugares para ampliar a possibilidade de 0 indivíduo atuar em sociedade e sobre o meio ambiente de forma responsável, buscando contribuir para um desenvolvimento sustentável.

Assim, o problema que se quis responder com a realização do trabalho foi: qual a percepção dos egressos do curso quanto à sua formação no que se refere a $E A$ ?. Como forma de responder a esse questionamento, o estudo teve início no primeiro semestre de 2018, sendo que os sujeitos da pesquisa foram os egressos das turmas formadas nos 5 (cinco) anos anteriores. O objetivo principal foi realizar uma investigação sobre as percepções que os egressos possuem sobre o seu processo formativo voltado a EA e a prática docentes dos formadores, durante o seu percurso acadêmico. 


\section{Metodologia}

Os sujeitos deste estudo são os egressos de um Curso de Licenciatura em Ciências Naturais - CLCN, ofertado na modalidade presencial de uma IES do arquipélago do Marajó no Estado do Pará.

A pesquisa foi desenvolvida nas seguintes etapas distintas:

Primeira etapa: o estudo teve início no primeiro semestre de 2018, com o levantamento das informações de contato dos sujeitos da pesquisa que foram os egressos das turmas formadas nos últimos 5 (cinco) anos, sendo que houve a divisão dos grupos por turma. Assim os grupos foram identificados como CN2012, CN2013, CN2014, CN2015A, CN2015B e CN2016; para essa identificação foi levado em consideração o ano de entrada dos sujeitos de cada grupo. A forma de contato foi através de e-mail.

Segunda etapa: elaboração do formulário de perguntas, seleção das disciplinas que, de acordo com sua ementa, foram colocadas em questão para obtenção de parte dos dados da pesquisa e envio do formulário por e-mail.

Terceira etapa: análise, interpretação e tabulação dos dados obtidos a partir das respostas dos sujeitos da pesquisa. Nessa etapa também foram criados os meios para o aferimento dos dados obtidos das questões abertas.

Para alcançar o objetivo central da pesquisa, que foi investigar as percepções dos egressos do CLCN de uma IES sobre sua formação voltada à $E A$, bem como delinear alguns desdobramentos que essa investigação proporciona, foi utilizado como instrumento de coleta de dados um formulário, conforme descrito anteriormente na segunda etapa do percurso metodológico. O questionário caracterizou-se pela possibilidade de ampliar conhecimentos e experiências mediante 0 uso de perguntas dirigidas a pessoas ligadas diretamente ao fenômeno estudado (GIL, 2008).

Para composição de algumas das questões realizadas foi utilizada nas alternativas de respostas a escala Likert de concordância de frases, solicitando-se que o sujeito da pesquisa optasse por uma resposta de acordo com o quanto ele concordasse ou discordasse de uma frase. Para tal, utilizou-se cinco possíveis respostas em uma escala, em que a nota mínima seria assinalada discordo totalmente e a nota máxima na alternativa concordo totalmente.

\section{Resultado e discussão}

Os contatos de e-mail dos egressos do curso, formados nos últimos 5 anos, foi levantado através do Sistema Integrado de Gestão de Atividades Acadêmicas da Universidade. Assim, foram obtidos os e-mails de 27 egressos da turma CN2012, 20 da turma CN2013, 20 da turma CN2014, 25 da turma CN2015A e 17 da turma CN2015B e de 24 da turma CN2016, totalizando 133 participantes que foram contatados, dos quais 110 colaboraram com a pesquisa, representando $82,17 \%$ da amostragem.

A participação dos egressos na pesquisa foi tabulada por turma, sendo que os percentuais de participação de cada turma foram os seguintes: CN2012 
(48,15\%), CN2013 (70,00\%), CN2014 (95,00\%), CN2015A (96,00\%), CN2015B $(95,12 \%)$ e CN2016 (100\%). O baixo percentual de participação dos egressos da turma CN2012 pode estar relacionado com a desatualização do cadastro destes no sistema, pois há aproximadamente 4 anos desde que eles integralizaram o curso.

No que se refere ao formulário eletrônico, foi constituído por 13 questões fechadas e 2 abertas. Iniciado com a apresentação do Termo de Consentimento Livre e Esclarecido (TCLE), no qual constavam as informações sobre o escopo do estudo, objetivos, responsáveis, dentre outras, seguido da opção de aceitar ou não aceitar participar do estudo. Todos os 110 sujeitos que responderam o formulário, acessado através de um link enviado para os endereços de e-mail dos participantes, aceitaram participar do estudo após a leitura do TCLE.

Quanto a constituição do formulário este pode ser dividida em três partes, conforme as três linhas de interesse dos autores da pesquisa, que objetivam os seguintes aspectos: na primeira buscou-se compreender a percepção dos participantes a respeito da formação voltada à EA que lhes foi apresentada. A segunda parte foi destinada a verificação do conhecimento adquirido pelo egresso e sua percepção sobre seu comprometimento com os temas voltados à EA. E a terceira foi referente a autoanálise sobre o percurso acadêmico do egresso, em associação ao interesse deste em continuar se qualificando. Por último foram aplicadas duas perguntas abertas, cuja discussão foi realizada com base na análise de conteúdo.

Analisando as respostas da primeira linha de interesse dos autores do estudo, pode-se observar os seguintes resultados com suas discussões:

A primeira questão do formulário teve como objetivo investigar se os discentes foram instigados a trabalhar em suas futuras práticas os conteúdos sobre EA dada sua importância, logo foi realizada a seguinte pergunta: "Durante as disciplinas que envolveram os temas Ambientais, ficou claro para você a importância de se discutir com os alunos o tema?". Foram apresentadas como alternativas de respostas as seguintes opções: Não, Um pouco, Bastante e Totalmente.

Observou-se que $84,5 \%$ dos discentes, quando somados os percentuais atribuídos as respostas "Bastante" e "Totalmente", que ficou clara a importância de se trabalhar a EA. Porém, os cerca de $15,5 \%$ de respostas obtidas quando somados os resultados para as opções "Não" e "Um pouco" dispara um alerta sobre a possível necessidade de ser mais enfática pelos formadores a importância de se discutir os temas voltados a EA.

A segunda questão foi: "Dentre as disciplinas abaixo ofertadas durante seu curso, relacione ao nível de formação voltado a Educação Ambiental". Esta questão foi formulada com base no PPC do curso, de onde foram selecionadas 08 (oito) disciplinas obrigatórias nas quais termos como fauna, flora, preservação, ecossistemas, ambiental, Amazônia, floresta, constavam no texto das respectivas ementas. Em cada disciplina selecionada, havia 05 (cinco) 
opções a serem selecionadas pelos participantes, que foram instruídos a marcar apenas uma delas em cada uma das disciplinas julgadas por eles.

A partir do gráfico ilustrado na Figura 1, pode-se observar que, quando somados os resultados para os que indicaram as disciplinas ministradas no curso como sendo "Excelente", "Muito bom" e "Satisfatório", as disciplinas que foram mais bem avaliadas, de forma decrescente de percentual, foram: Fundamentos de ecologia na Amazônia (84\%); Química do Solo e da Água (82\%); Química e Atmosfera (79\%); Ecologia Básica (74\%), Energia, Química e Sociedade (75\%); Botânica II (72\%); Botânica I (69\%) e Física da Terra e do Universo (57\%). Com base nos dados obtidos, pode-se inferir que as três primeiras disciplinas foram classificadas como boas e as demais como regulares.

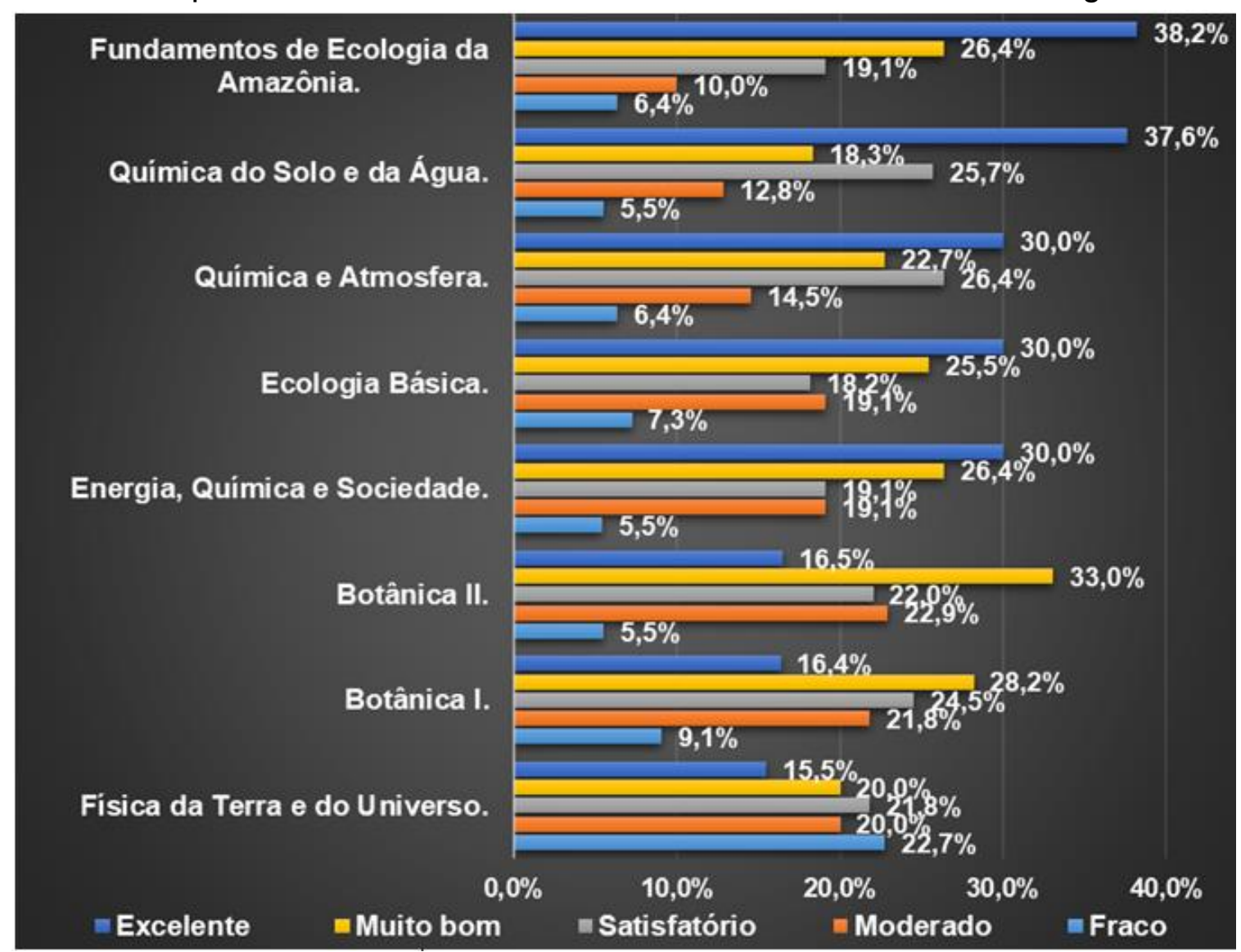

Figura 1: llustração gráfica com os dados obtidos a partir das respostas da questão 02.

Fonte: Dados da pesquisa.

Vale ressaltar que as disciplinas investigadas neste trabalho, e que são ofertadas no CLCN, cumprem sua finalidade e, entende-se, vão além do estabelecido em seus escopos, pois apenas as disciplinas da área de química fazem menção em suas ementas a temas relacionados a questões ambientais. Isso está relacionado com a elaboração do Projeto Pedagógico do Curso, que data do ano 2011, anterior à Resolução $n^{\circ} 2$, de $1^{\circ}$ de julho de 2015, do Ministério da Educação (BRASIL, 2015), estabelece em seu Art.12 que cursos de Licenciatura constituam em seus núcleos, projetos e estudos relacionados a EA. 
A verificação da terceira questão foi com base na seguinte pergunta: "Quando você estudou sobre os temas ambientais, o conteúdo e a metodologia empregada pelo(a) professor(a) foram.". Esta questão permitiu identificar quais foram os principais fatores aplicados pelos docentes que ministraram as disciplinas, que puderam contribuir ou não com a apresentação dos temas voltados a EA (Figura 2). Para restringir o espectro de possíveis fatores, foram apresentados os seguintes itens: Os objetivos foram claros?; O conteúdo do curso foi organizado e bem planejado?; A carga do curso foi apropriada?; O curso foi organizado para permitir a participação de todos os alunos?. Sendo que em cada item o egresso poderia selecionar uma alternativa de acordo com o seu critério de concordância.

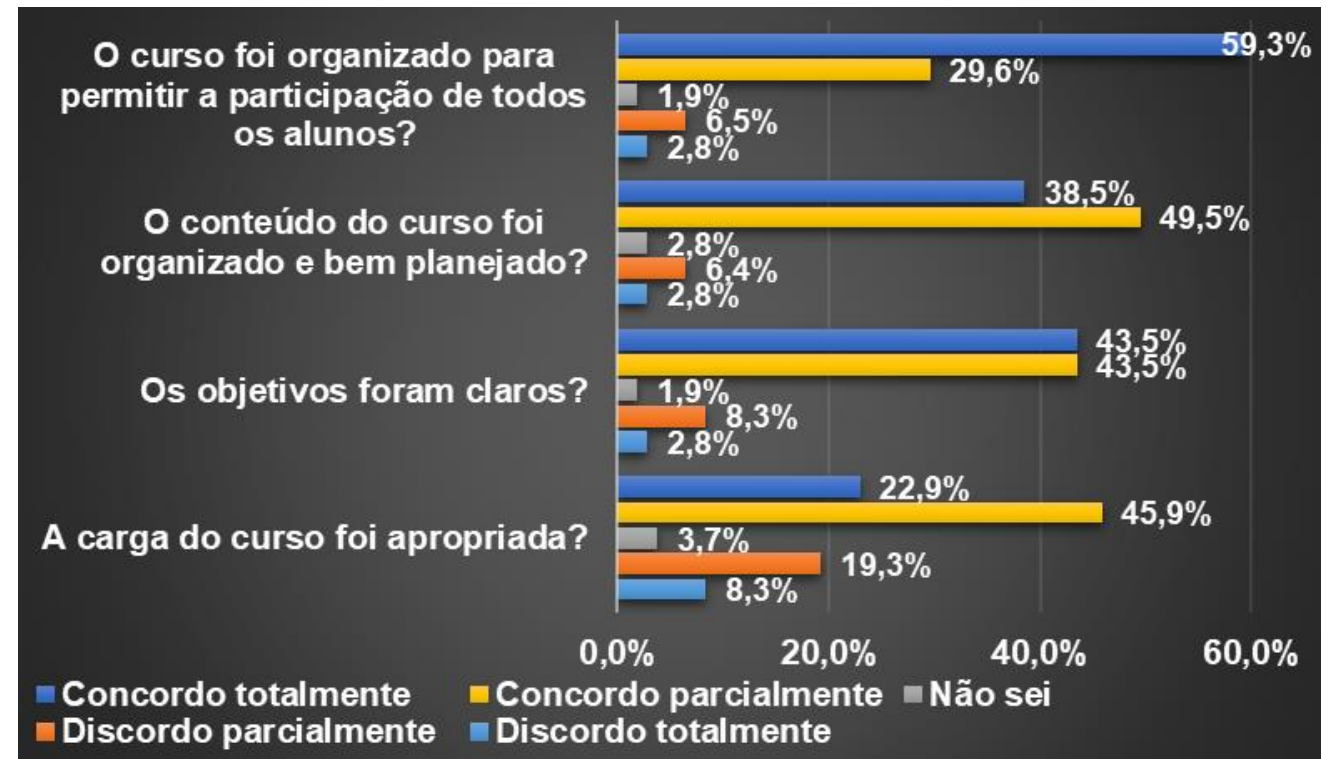

Figura 2: Ilustração gráfica com os dados obtidos a partir das respostas da questão 03.

Fonte: Dados da pesquisa.

Assim, a partir do gráfico ilustrado na Figura 2, pode-se observar que dos fatores apresentados para avaliação, os quais foram mais indicados com nível de concordância total ou parcial foram, respectivamente: $O$ conteúdo do curso foi organizado e bem planejado? (89\%); O curso foi organizado para permitir a participação de todos os alunos? (89\%) e Os objetivos foram claros? $(88 \%)$. Os excelentes resultados obtidos para três dos quatros fatores investigados revelam que as estratégias empregadas pelos docentes, influenciaram positivamente a formação dos egressos. $O$ fato que carece de melhor atenção é $A$ carga do curso foi apropriada? (69\%), não que o resultado percentual seja alarmante, porém a carga horária destinada para tratar sobre os temas voltados a EA deve ser vista com maior atenção. Uma possível causa para o percentual encontrado para a carga horária do curso pode estar relacionada com a oferta das disciplinas durante o curso que são ministradas na modalidade de blocos, ou seja, uma inicia apenas com o término da outra, tanto no regime extensivo, quanto no intensivo. 
Outra investigação foi baseada nos principais temas abordados no ensino de EA. Os temas analisados foram os mais relevantes para serem trabalhados por futuros professores que provavelmente estão ou irão atuar na região. Para tal análise os temas foram apresentados, conforme descritos da figura 3 , e os sujeitos puderam atribuir conceitos a cada um deles, com base na forma com que estes Ihes foram apresentados.

A partir dos dados obtidos, ilustrado no gráfico na Figura 3, verifica-se que todos os temas investigados foram considerados aprovados pelos egressos, pois o resultado "Insuficiente" não ultrapassa os $16,5 \%$ da amostragem. Também pode-se observar que, se somados os percentuais atribuídos aos conceitos "Excelente" e "Bom", em todos os temas, observa-se valores superior a $60 \%$. Dessa análise destacam-se dois temas: O primeiro Descarte de Óleos de frituras em pias, rios, igarapés etc. - por ter apresentado maior percentual de "Insuficiente" (16,5\%), chama a atenção pois devido a própria natureza da região, cercada por furos, rios, lagos e igarapés, como explanado por Freitas et al. (2020), deveria ser abordada com maior atenção. No segundo - Preservação da fauna e da flora - os dados revelam o maior percentual para a opção "Excelente" (63,9\%), o que corrobora os dados apresentados para análise da disciplina (Fundamento de Ecologia na Amazônia), discutida como base na Figura 1, pois o tema é contemplado na oferta da referida disciplina.

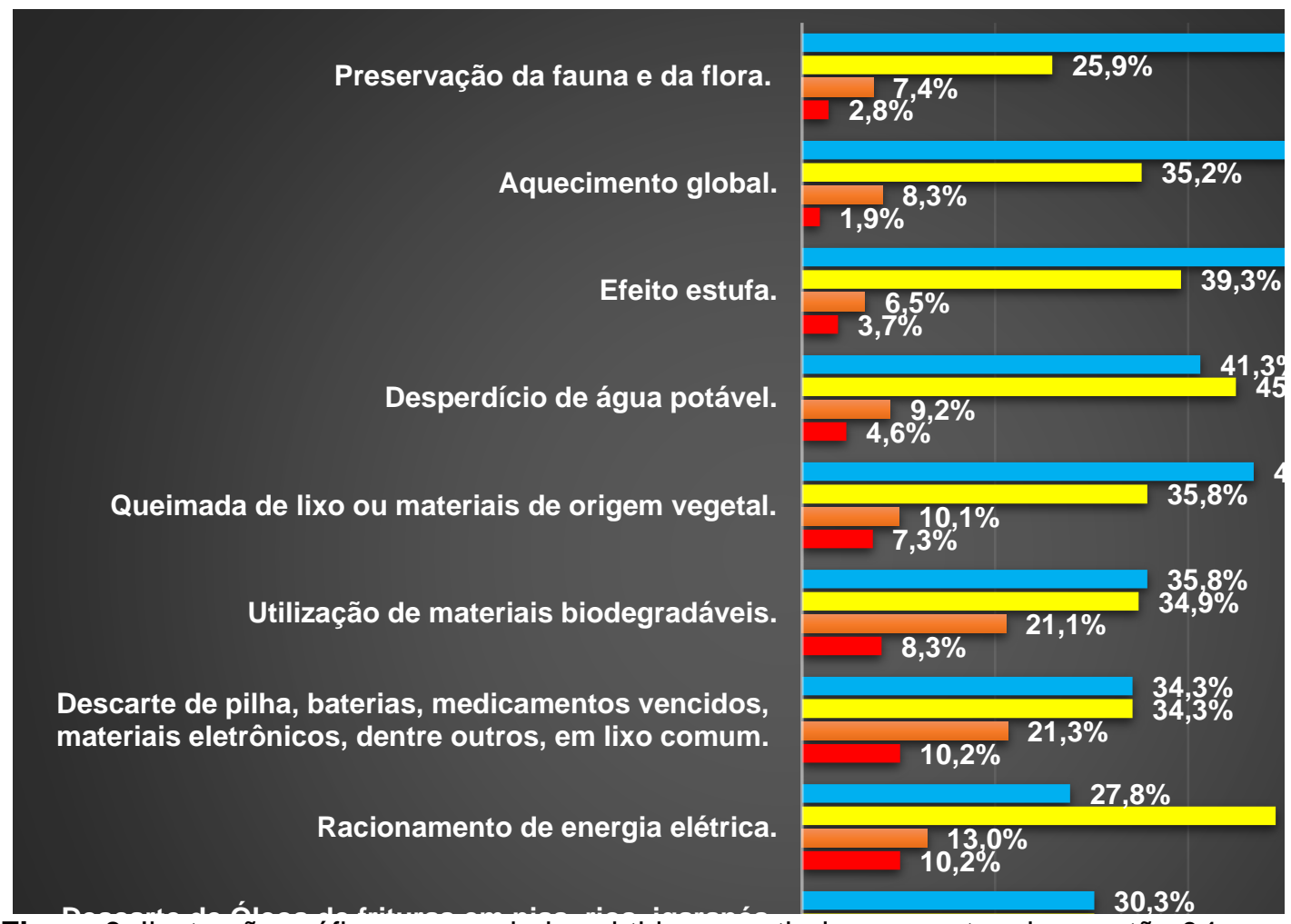

Figura 3: llustração gráfica com os dados obtidos a partir das respostas da questão 04 .

Fonte: Dados da pesquisa. 
$\mathrm{Na}$ quinta questão chega-se ao fim da sequência de discussões sobre a primeira parte do formulário (Figura 4). Assim, após a verificação das disciplinas ofertadas, os fatores que contribuíram para execução das disciplinas e os temas (tópicos) mais pertinentes para serem discutidos em EA na região amazônica, foram investigados a partir da seguinte questão - Qual a metodologia mais empregada para lhe apresentar os tópicos sobre Educação Ambiental? Relacione de forma apropriada.

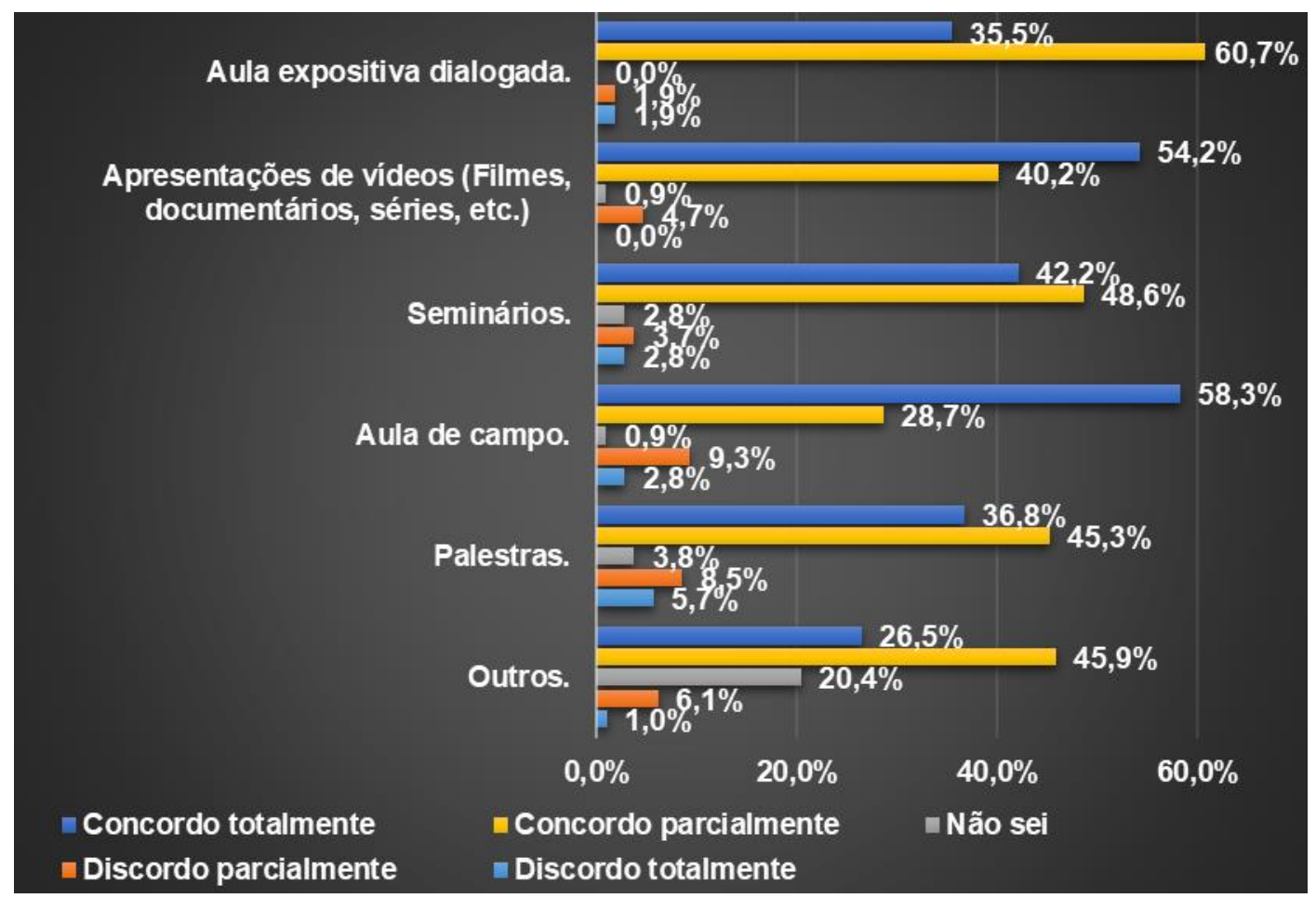

Figura 4: llustração gráfica com os dados obtidos a partir das respostas da questão 05.

Fonte: Dados da pesquisa.

A partir dos dados apresentados no gráfico ilustrado na Figura 4, verifica-se que as metodologias mais empregadas foram: Aula expositiva dialogada; Apresentações de vídeos (Filmes, documentários, séries etc.) e Seminários, estas apresentaram concordância, total ou parcial, acima de $90 \%$ quando somados os valores obtidos para cada uma. Portanto, estas foram as metodologias mais utilizados pelos docentes que ministraram as disciplinas que possuíam os temas voltados a EA. Assim a primeira parte do formulário foi finalizada.

A segunda parte do formulário pode ser compreendida como uma forma de investigar o grau de conhecimento adquirido pelo egresso e seu envolvimento/comprometimento com a EA.

Como início da segunda parte foi realizado o seguinte questionamento: "Você conhece a Política Nacional de Resíduos Sólidos?". Essa questão foi interessante, pois a consequência de conhecer a referida política traz para o profissional um grande espectro de informações que se traduz na capacidade 
de trabalhar em sala de aula ações formais e extrapolar para ações nãoformais. Foram apresentadas como alternativas de respostas as seguintes opções: Nunca ouvi falar, Conheço pouco, Conheço bastante e Sei tudo.

Pôde-se observar que a soma do percentual dos que responderam "sei tudo" (2,7\%) e "conheço bastante" (57,3\%), não supera $60 \%$ da amostragem. Este resultado revela que a Política Nacional de Resíduos Sólidos (PNRS), deve ser mais trabalhada na formação dos futuros professores de ciências. Não somente esta política pública sancionada pela Lei oㅜ 12.305, de 2 de agosto de 2010 (Brasil, 2010), mas, também as outras políticas públicas ambientais importantes, como a Política Nacional de Recursos Hídricos (Instituída pela Lei oㅜ 9.433, de 8 de janeiro de 1997) e o Novo Código Florestal (Lei no 12.651/2012), que são de suma importância para serem inseridas e discutidas no processo educativo voltado à EA, principalmente, em um curso que forma profissionais que atuarão nesta região tanta vascularizada que é a Amazônia.

A próxima questão da segunda parte não foi menos importante que a primeira, pois mais assustador do que não conhecer um assunto tão importante para o bem-estar social como a PNRS é não saber sobre suas consequências. Assim foi realizada a seguinte pergunta: "Você conhece os prováveis problemas ambientais causados pelo descarte inapropriado de Resíduos sólidos?'. Foram apresentadas como alternativas de respostas as seguintes opções: Não faço ideia, Conheço pouco, Conheço bastante e Sei tudo.

Pôde-se observar que a soma do percentual dos que responderam "sei tudo" $(6,4 \%)$ e "conheço bastante" $(71,8 \%)$, não supera $80 \%$ da amostragem, porém observa-se um aumento significativo de $18,2 \%$ se comparado com os dados da questão anterior para a mesma faixa de respostas (sei tudo e conheço bastante). Esse aumento de $18,2 \%$ sugere que mesmo os que nunca ouviram falar sobre a PNRS (2,7\%), sabem dos prováveis problemas ambientais causados pelo descarte inapropriado de resíduos sólidos.

A oitava questão foi enunciada da seguinte forma: "Você alguma vez já aplicou ou compartilhou os conhecimentos adquiridos durante sua formação em seu convívio familiar ou social? Relacione as questões abaixo com o nível mais adequado". Por meio desta, procurou-se investigar se os egressos estão colocando em prática o conhecimento adquirido durante a formação acadêmica. Para tal investigação foram apresentados os mesmos temas/tópicos, presentes no gráfico ilustrado na figura 5, para que os sujeitos da pesquisa relacionassem com o nível mais adequado de acordo com suas concepções. As opções de relação com os temas/tópicos, foram: Sempre falo; Às vezes; Ao menos uma vez e Nunca.

O gráfico ilustrado na Figura 5 , contém os resultados obtidos para a pergunta em questão. Logo, pode-se observar que o tema Desperdício de água potável foi relacionado por $75,5 \%$ dos sujeitos como o tema que estes sempre falam. O resultado reflete a própria realidade vivida na região, pois não há um sistema de tratamento água potável que supra as necessidades de forma 
adequada das populações que habitam a região da Amazônia marajoara. $\mathrm{O}$ segundo tema que os sujeitos da pesquisa indicaram como Sempre falo foi a Preservação da fauna e da flora, alcançando um percentual de $73,4 \%$ das respostas dadas como opção. Este resultado pode ser interpretado como controverso, pois sabe-se que culturalmente os povos amazônicos são, em sua maioria, caçadores e pescadores, não sendo muito difícil de ser encontrado em feiras, carnes de animais silvestre. Mendes e Simonian (2016) reportam em estudo que as populações de várias cidades no estado Pará, principalmente as que estão localizadas as margens de rios da Amazônia (Tocantins e Amazonas), são consumidores de carnes de animais silvestres.

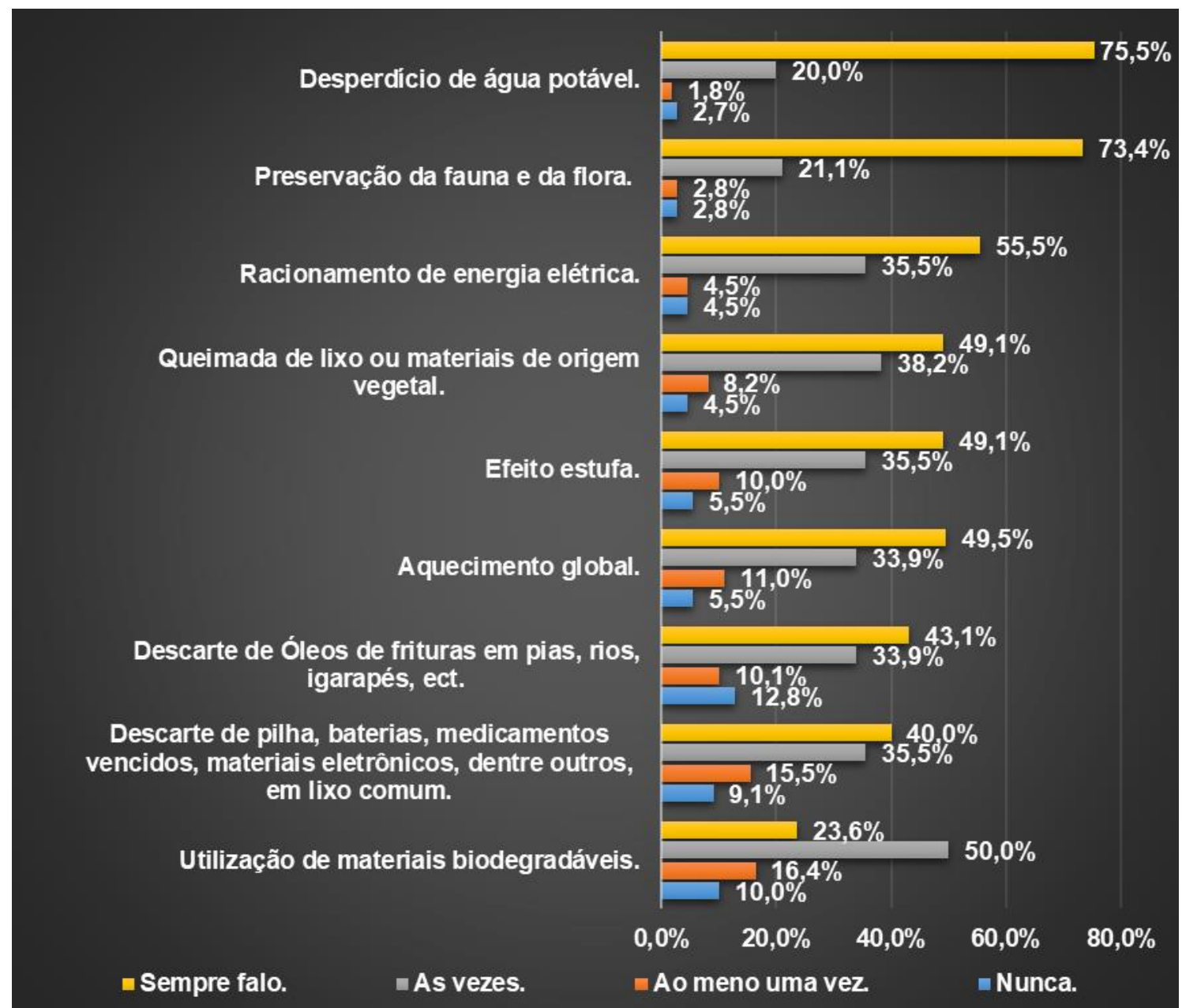

Figura 5: llustração gráfica com os dados obtidos a partir das respostas da questão 08.

Fonte: Dados da pesquisa. 
É, pois, imprescindível saber o que os egressos pensam a respeito da formação recebida para se proceder a ajustes em todas as partes do sistema de ensino ofertado. Além disso, conhecer o que fazem como profissionais e cidadãos e suas adequações aos setores em que atuam, possibilita uma reflexão crítica sobre a formação e sua relação com as necessidades do mercado de trabalho.

Assim o desenvolvimento desta pesquisa é capaz de responder algumas questões sobre o modelo de formação de professores que vem sendo aplicado na IES lócus do estudo (Figura 6).

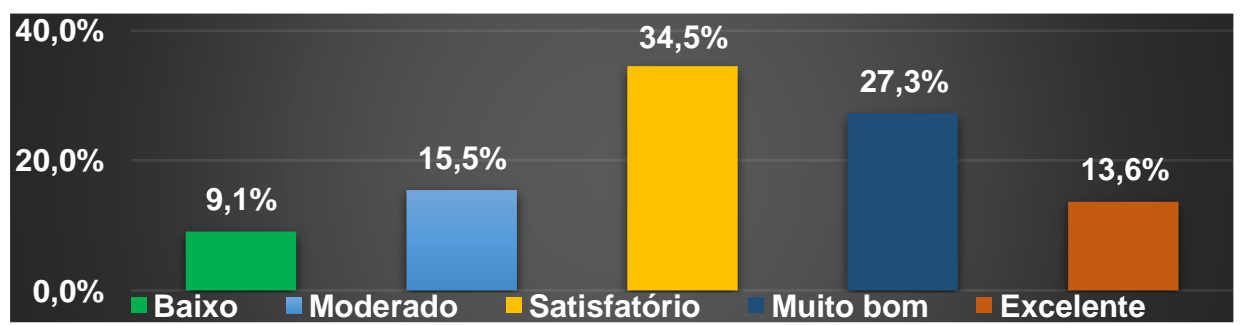

Figura 6: llustração gráfica com os dados obtidos a partir das respostas da questão 06.

Fonte: Dados da pesquisa.

A partir dos dados apresentados no gráfico ilustrado na Figura 6 e levando em consideração como sendo positivos os resultados Excelente $(13,6 \%)$, Muito bom (27,3\%) e Satisfatório (34,5\%), para a questão investigada, tem-se que para $75,4 \%$ dos sujeitos a formação voltada à EA que the foi aplicada em seu percurso acadêmico pode ser considerada satisfatória. Segundo Branquinho (2012, p. 24), "A satisfação do egresso é um fator que deve ser explorado e se torna um indicador da qualidade tanto da sua formação quanto da prestação de serviço", assim a busca pela excelência na formação de professores sempre será almejada pelos formados.

Além de verificar o quanto os egressos estão ou não satisfeitos com a formação volta a EA, outra questão de imensa relevância de ser avaliada foi instigada na seguinte pergunta: "Em sua futura prática quanto professor, você irá enfatizar os temas ambientais em suas aulas?'. Branquinho (2012, p. 24), faz a seguinte afirmação sobre o egresso:

Quando este está satisfeito se envolve com processos de avaliação da adequação da estrutura pedagógica do curso que foi vivenciado, e dos aspectos intervenientes desse processo na formação acadêmica assim como em colocar em pratica o que melhor adquiriu na sua formação.

Como opções de possíveis respostas para a referida pergunta, os sujeitos puderam optar por: Pouco provável, ou Talvez, ou Provavelmente. 
Como base nos dados obtidos, pode-se inferir a partir do desenvolvimento dos temas/tópicos que abordaram a EA, que houve formação de um olhar sensível ou mudança de atitude por parte da grande maioria dos sujeitos, no sentido de se importarem com as questões relativas ao meio ambiente, pois $97,3 \%$ afirmaram que provavelmente irão enfatizar os temas ambientais em suas práticas docentes.

Os egressos foram instigados a refletirem sobre o quanto eles se sentem preparados para ministrar assuntos relativos ao meio ambiente. Para se ter um entendimento sobre a questão, foi realizada a seguinte pergunta: "Você se sente preparado para ministrar assuntos sobre meio ambiente?". Como opções de resposta, foram dadas 4 alternativas (Totalmente, Sim, Talvez, Não).

A partir da análise das respostas observou-se que $31,8 \%$ responderam "Totalmente" e 55,5\% que "Sim", se sentem preparados para pôr em prática os conhecimentos sobre meio ambiento. Estes resultados são considerados positivos, pois a somas dos percentuais das respostas (Totalmente e Sim), ultrapassam $87 \%$ da amostragem. Porém, existem estes $0,9 \%$ e $11,8 \%$, que responderam, respectivamente, "Não" e "Talvez", os quais são resultados considerados pontos negativos, que precisão ser observados com maior atenção no sentido de mitigar ou corrigir este ponto.

Estudos sobre a importância da formação continuada para professores de ciências é algo que vem sendo discutido por muitos pesquisadores, porém, como afirmam Moro e Dullius (2019), há uma grande escassez em formações voltadas as series finais do ensino fundamental maior, principalmente relacionados a EA.

Um primeiro passo no sentido mitigar o percentual $12,7 \%$, resultado considerado negativo na questão anterior, foi dado ao verificar se há interesse por parte dos egressos, que a faculdade em que eles foram formados ofertasse formação continuada a eles. Pois como afirmam Lima e Santos (2017, p. 62) que "os cursos de formação e espaços de discussão, e de transformação, das práticas vivenciadas no dia a dia da sala de aula, ultrapassando a ideia de que representem apenas uma oportunidade de atualização de conhecimentos", assim a criação desses espaços potencializa o crescimento pessoal e profissional do professor, fazendo com que este tenha maior confiança e se sinta mais confortável para ministrar diferentes assuntos em sala de aula.

Para Lima e Santos (2017, p. 61), neste contexto de proporcionar formação continua a professores de ciências, estes vêm que "as universidades desempenham um relevante papel na organização de ações voltadas ao desenvolvimento da professoralidade". Logo, foi realizada a seguinte pergunta: Você gostaria que a Faculdade ofertasse formação continuada em EA a egressos do curso?. Como alternativas de possível resposta foram apresentadas as seguintes opções: Não, Talvez, e Sim.

Observa-se, que $92,7 \%$ responderam "Sim", 6,7\% "Talvez" e 0,9\% 
a soma de $31,8 \%$ e $55,5 \%$ dos que responderam "Totalmente" e "Sim", respectivamente para questão anterior (Você se sente preparado para ministrar assuntos sobre meio ambiente?), o resultado (92,75\%) é superior em $5,45 \%$, o pode ser interpretado como se mesmo para os que se sente totalmente preparados para ministrar temas sobre meio ambiente, estes gostariam que fosse ofertada formação continuada.

Para finalizar a terceira parte do formulário foi realizada a seguinte pergunta: Você participaria de eventos (Minicursos, palestras, oficinas, encontros) voltados a questões ambientais?. Essa questão foi realizada para avaliar o grau de comprometimento dos sujeitos com a disponibilização de eventos pela Faculdade, pois uma questão é assinalar como interessante ou que seja necessária a realização de evento de formação continuada, outra é participar da formação.

Obteve-se que $89,1 \%$ dos egressos responderam que "Sim", participariam de minicursos, palestras, oficina, encontros, dentre outros, promovidos pela faculdade. Este resultado revela que existe um nicho para ser trabalho, onde depende inicialmente da criação de espaços para que haja discussões sobre propostas de cursos que abarquem este nicho.

\section{Análise de conteúdo}

O questionário utilizado como instrumento de coleta, conforme dito anteriormente, possuía duas questões abertas, a saber: (i) "Quais aspectos deste curso foram mais úteis ou valiosos para sua formação (processo educativo) voltada à Educação Ambiental?" e; (ii) "Como você melhoraria as atividades voltadas para Educação Ambiental?'. Em relação aos dados destas questões, foi realizada uma análise de conteúdo, a qual, segundo Flick (2013, p. 134) tem como objetivo "classificar o conteúdo dos textos alocando as declarações, sentenças ou palavras a um sistema de categorias.". Assim, as respostas dos participantes foram categorizadas a posteriori nos pontos de convergência que estão exemplificados no Quadro 1.

Quadro 1: Exemplo de categorização realizada nas respostas dos participantes à questão aberta "quais aspectos deste curso foram mais úteis ou valiosos para sua formação (processo educativo) voltada à EA?".

\begin{tabular}{|l|c|}
\hline Resposta à questão aberta 1 & Categorização \\
\hline $\begin{array}{l}\text { O conhecimento da EA relacionada com os temas socioambientais, } \\
\text { saindo apenas do conservadorismo e analisando com uma visão } \\
\text { mais crítica. }\end{array}$ & Discussões \\
\hline $\begin{array}{l}\text { Aspectos trabalhados com a temática de resíduos sólidos, foi sem } \\
\text { dúvida muito importante, pois os resíduos sempre serão gerados } \\
\text { todos os dias e saber lidar com esses matérias é sem dúvida muito } \\
\text { importante para nós seres humanos e para o próprio meio ambiente. }\end{array}$ & $\begin{array}{c}\text { Temática de } \\
\text { resíduos sólidos }\end{array}$ \\
\hline $\begin{array}{l}\text { Um minicurso voltado para Educação Ambiental, Eco 92 e sobre a } \\
\text { carta da terra. }\end{array}$ & Minicursos \\
\hline $\begin{array}{l}\text { Fiquei totalmente satisfeito com a metodologia do curso, aula prática, } \\
\text { oficinas, teórica e prática. }\end{array}$ & $\begin{array}{c}\text { Metodologia } \\
\text { Aulas práticas } \\
\text { Conteúdo teórico }\end{array}$ \\
\hline
\end{tabular}

Fonte: autoria própria. 
Entretanto, esta categorização inicial gerou 30 categorias, as quais a análise não seria prática. Desse modo, algumas categorias cujos significados eram semelhantes foram agrupadas em uma categorização secundária, de acordo com o exemplificado no Quadro 2.

Quadro 2: Exemplo de categorização secundária realizada.

\begin{tabular}{|l|c|}
\hline Categorização inicial & Categorização secundária \\
\hline Conteúdo teórico & \\
Temática de energia limpa & \\
Temática de resíduos sólidos & Conteúdo teórico \\
Temática de problemas ambientais cotidianos & \\
Palestras & \\
Aulas & \\
Aulas expositivas & Prática \\
\hline Prática & \\
Aulas práticas & \\
Projetos & \\
\hline
\end{tabular}

Fonte: autoria própria.

A partir desta categorização secundária foram geradas 15 categorias que puderam, enfim, ser analisadas. Na Figura 7, estão apresentadas as ocorrências de cada categoria nas respostas dos participantes.

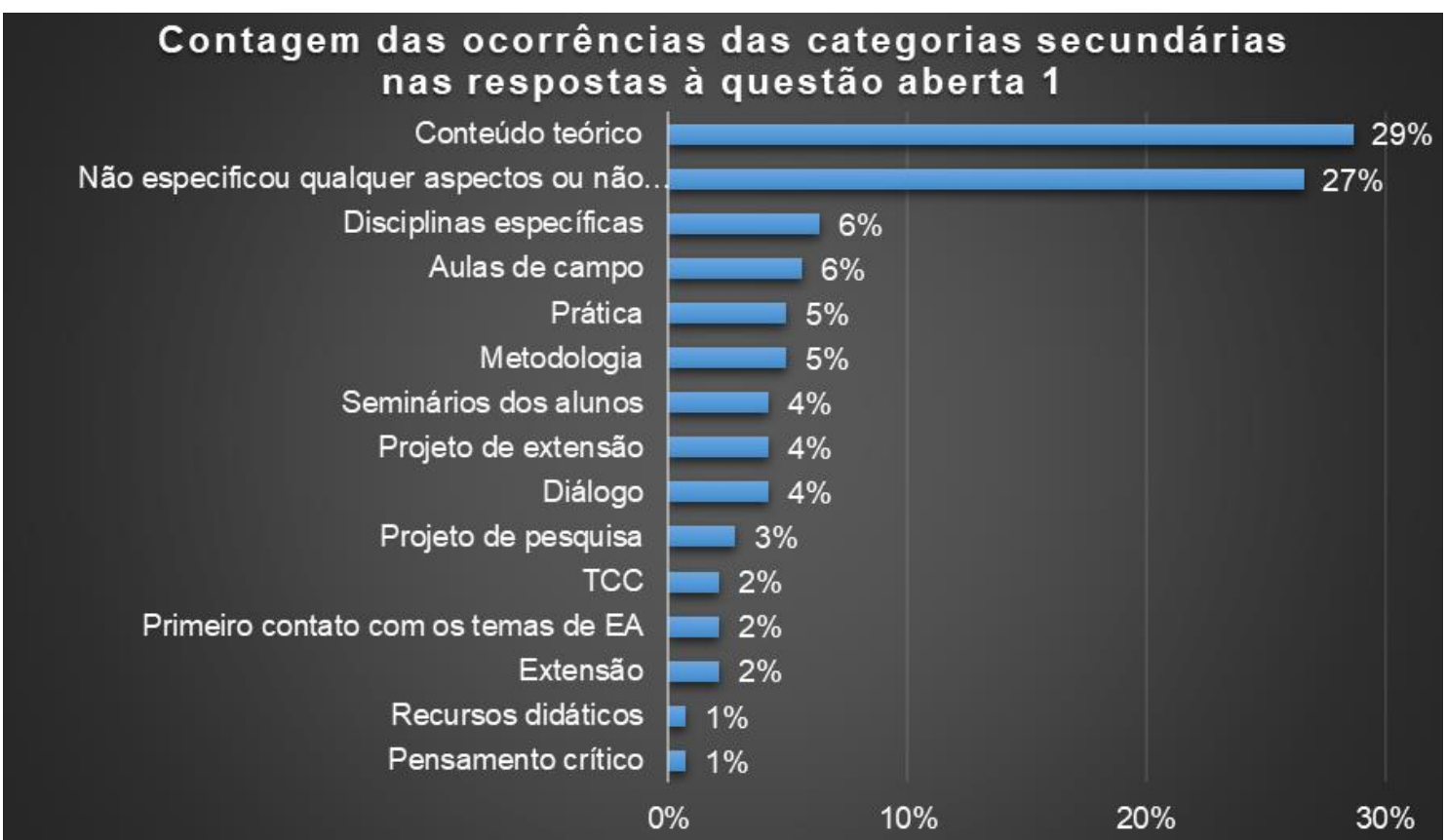

Figura 7: Ocorrências das categorias secundárias nas respostas dos participantes à primeira questão aberta. Fonte: dados da pesquisa.

Dentre estas 15 categorias elaboradas foi incluída a categoria não especificou qualquer aspecto ou não respondeu, na qual se fez a contagem de 38 participantes que não responderam a questão por deixa-la em branco ou por não apresentar pelo menos um aspecto do curso que foi útil para 
processo/formação voltada à EA. Assim, 27\% dos participantes não responderam, de fato, a primeira questão aberta do formulário.

A categoria que foi mais frequente nas respostas dos participantes foi a relacionada ao conteúdo teórico trabalhado durante o curso $(29 \%$ das citações). Conforme apresentado no Quadro 2, esta categoria englobava diversos elementos do curso que estariam relacionados ao conteúdo teórico em si, tais como as aulas expositivas, as palestras, os minicursos e temáticas específicas (como de resíduos sólidos, por exemplo). É interessante destacar que a quinta questão objetiva da primeira parte do formulário mostrou que aulas expositivas dialogadas foi uma das metodologias mais empregadas na abordagem de temas voltados à EA. Assim, pode-se considerar que a presença marcante deste tipo de metodologia, na qual a abordagem de conteúdo teórico é predominante, não pode ser considerada como um ponto negativo do curso, pois foi relacionada com um dos aspectos mais úteis para o processo formativo voltada à EA.

Adicionalmente a esta análise, pode-se acrescentar o segundo aspecto mais frequente nas respostas dos participantes, que foi o das disciplinas específicas, citada em $6 \%$ das categorias. Nesta categoria, os participantes citaram disciplinas do Projeto Pedagógico do Curso que estão diretamente ligadas à EA, tais como: (i) Fundamentos da Ecologia; (ii) Química, Energia e Sociedade; (iii) Química do solo e da água; (iv) Ecologia da Amazônia, dentre outras. Por serem disciplinas nas quais o conteúdo teórico é mais voltado à $E A$, pode-se considerar que, pelo menos parcialmente, esta categoria está relacionada também ao conteúdo teórico do curso. Assim, 35\% dos aspectos citados pelos participantes como positivo à formação em EA estava relacionado ao conteúdo teórico do curso.

Por outro lado, considerando as categorias aula de campo e práticas, percebe-se que $11 \%$ dos aspectos citados pelos participantes não estão relacionados diretamente ao conteúdo teórico. Embora em aulas de campo sejam abordados temas que estão relacionados ao conteúdo teórico do curso, entende-se que os participantes podem ter relacionado as aulas de campo também a um aspecto mais prático do curso, uma vez que estas aulas são baseadas na observação e coleta de espécimes diretamente do ambiente. Desse modo, pode-se entender que o conteúdo prático do curso foi citado como o segundo aspecto mais útil para a formação voltada à $E A$, porém com uma frequência bem mais baixa do que a das categorias relacionadas ao conteúdo teórico.

Por fim, metodologia, seminários realizados pelos alunos em sala de aula, projetos de extensão e o diálogo realizado durante as aulas, também foram aspectos citados pelos participantes como úteis para formação voltada à EA, porém com menor frequência.

Já em relação à segunda questão aberta, a saber "como você melhoraria as atividades voltadas para Educação Ambiental?", o processo de categorização foi semelhante ao executado na primeira questão aberta, 
resultando nas 16 categorias elaboradas a posteriori cujas ocorrências nas respostas dos participantes estão apresentadas no gráfico ilustrado na figura 8.

Dentre os 110 participantes da pesquisa, 30 não apresentaram qualquer sugestão de melhoria das atividades voltadas à $E A$, 0 que se configurou como a maior frequência dentre as categorias de resposta dos participantes (18\%). Este resultado é interessante porque a maior frequência desta categoria (em branco ou sem sugestão de melhoria) nos mostra que o número de participantes sem qualquer sugestão de melhoria é maior que a frequência de qualquer outra sugestão, o que pode ser interpretado como uma boa aceitação das abordagens de EA pelos participantes (Figura 8).

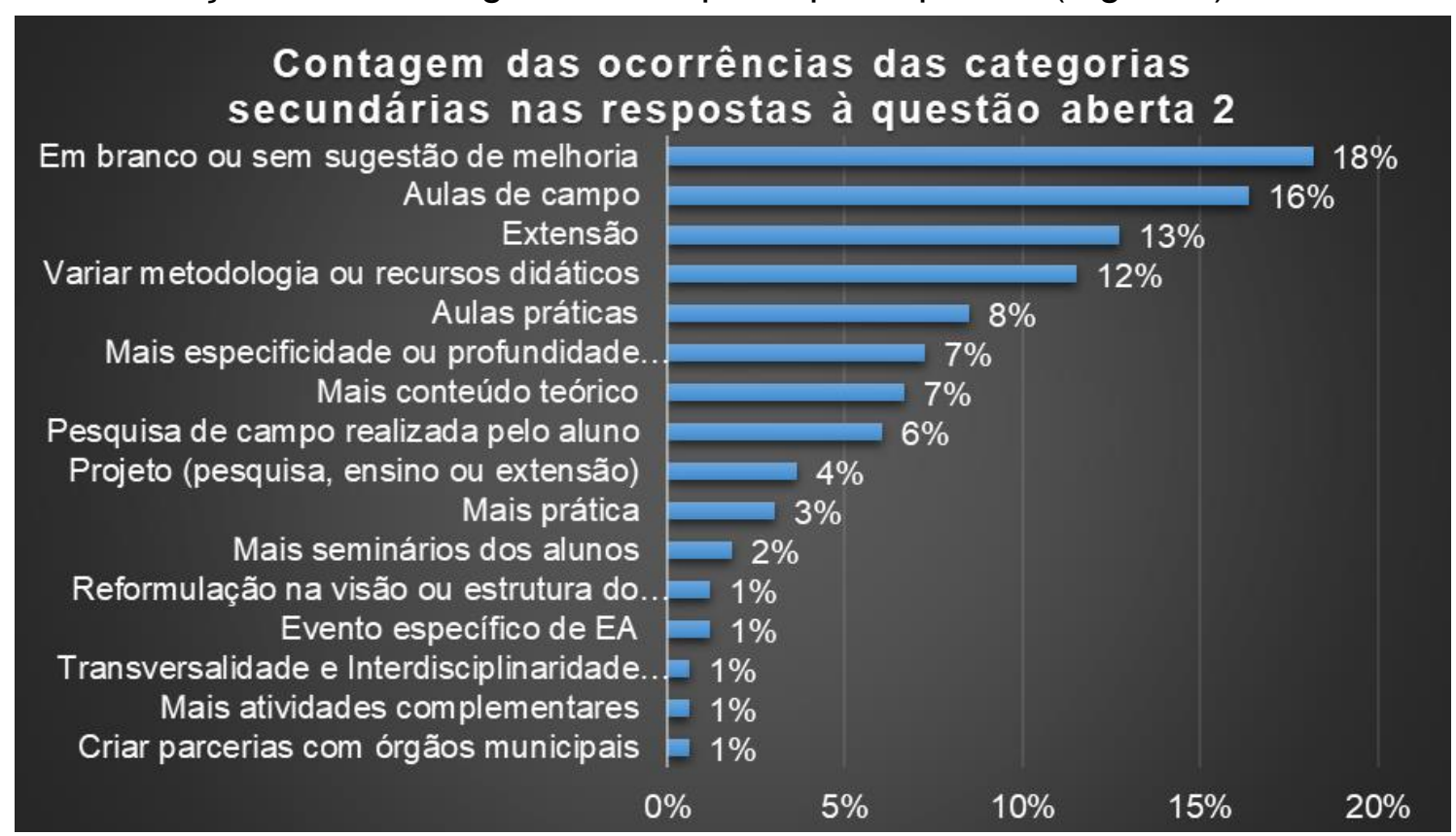

Figura 8: Ocorrências das categorias nas respostas dos participantes à segunda questão aberta. Fonte: dados da pesquisa.

A sugestão mais frequentemente citada dentre as demais foi a categoria aulas de campo (16\%). Nesta categoria, as falas dos participantes estavam relacionadas as aulas de campo em si, mas também ao "acesso ao meio ambiente", "visita a locais", "atividades fora do campus", "ter contato com a realidade" e "sair da sala de aula", dentre outras. Apesar da quinta questão objetiva - na qual foi questionado qual a metodologia mais empregada para lhe apresentar os tópicos sobre Educação Ambiental (Figura 4) - apresentar 87\% dos participantes concordando que a aula de campo é uma metodologia bastante empregada, ainda assim há uma forte sugestão de que esta metodologia seja ainda mais empregada na abordagem de tópicos de EA.

A segunda sugestão de melhoria mais frequente nas falas dos participantes está relacionada ao uso de atividades de extensão (13\%). Apesar de as atividades de extensão compartilharem da característica de serem externas à universidade, tal qual as aulas de campo, as primeiras estão mais 
relacionadas à propagação dos conhecimentos estudados na universidade para a comunidade externa. Dentre as falas dos participantes nesta categoria, encontramos "debate sobre EA com a sociedade", "divulgar em massa as estratégias já usadas", "mais palestras que envolvam a sociedade", "ações educativas fora do campus", "feiras culturais voltadas para o aluno $e$ sociedade", "orientar estudantes a ministrar palestras em escolas" dentre outras.

Cabe também uma análise conjunta das ocorrências destas duas categorias. Assim, um total de $29 \%$ dos participantes sugere que as ações envolvendo EA na universidade devem ser realizadas em ambiente externos a ela.

A terceira categoria mais citada entre as respostas dos participantes se refere a mudança das metodologias e materiais didáticos empregados na abordagem de EA (12\%). Dentre as falas dos participantes nesta categoria encontramos "abordar a EA transversalmente", "focar a EA para a região e 0 cotidiano local", "realizar experiências que facilitem a compreensão da EA" e "trabalhar com mais recursos audiovisuais além da aula expositiva" dentre outras. Comparando este resultado também com a quinta questão objetiva - a qual questiona qual a metodologia mais empregada para lhe apresentar os tópicos sobre Educação Ambiental (Figura 4) - que apresenta o resultado de que $94,4 \%$ dos participantes afirmam que a apresentação de vídeos é uma metodologia bastante empregada, ainda assim há uma forte sugestão de que os materiais e a metodologia empregados no curso sejam variados.

Importa ressaltar que dentre as respostas dos participantes categorizadas neste grupo, nenhuma questiona o uso de aulas expositivas, mas, de modo geral, apresentam metodologias ou materiais que podem ser adicionados a esta metodologia principal.

A quinta categoria mais presente nas respostas dos participantes foi a de aulas práticas. Embora estas respostas pudessem ser agrupadas na categoria discutida anteriormente, esta foi destacada aqui porque as falas dos participantes foram bastante específicas em relação a este tipo de metodologia. Dentre as respostas, encontramos "sair do meio teórico e ir para a prática", "contemplar a teoria e a prática", "aumentar carga horária de aulas práticas" e "práticas de sala de aula" dentre outras. Fica claro da fala dos participantes que eles se referem a aulas práticas não como aulas fora do ambiente de sala de aula, mas a atividades nas quais os estudantes podem realizar as atividades por si. Enquanto a simples mudança de local, metodologia ou materiais não subentende esta postura ativa do aluno, necessariamente.

\section{Conclusões}

Nesta pesquisa buscou-se traçar um perfil sobre a formação acadêmica, no aspecto processo educativo, voltada à EA dos egressos do CLCN, ofertado por uma instituição na ilha do Marajó-PA. Também foi possível investigar o nível de satisfação com a formação voltada à temática ambiental. 
Assim, pode-se concluir que, segundo a opinião da grande maioria dos egressos estes são muito satisfeitos.

Durante a formação acadêmica estes são instigados a abordarem temas voltados ao meio ambiente, deixando clara a importância de se trabalhar a temática. Porém, de acordo com os resultados desta pesquisa, deve-se enfatizar mais essa importância. As disciplinas investigadas neste trabalho que são ofertadas no CLCN cumprem sua finalidade e entende-se vão além, pois apenas as disciplinas da área de química fazem menção em suas ementas a temas relacionados a questões ambientais. Quando as disciplinas são ministradas, os objetivos de cada uma são claros, o conteúdo é organizado e bem planejado, permitindo a participação de todos os discentes, porém a carga destinada aos temas voltados ao meio ambiente precisa ser vista com maior atenção.

Os egressos do curso saem da instituição com um bom conhecimento sobre os temas voltados a EA. Com consciência crítica sobre causas e efeitos para a sociedade e ao meio ambiente. Os egressos mostraram-se satisfeitos com a instituição formadora e, também, observa-se que a maioria pretende ou tem interesse em participar de cursos, ofertados pela instituição, em nível de pós-graduação ou cursos de curta duração, tais como minicursos, palestras, oficinas dentre outros.

É evidente que o CLCN, oferta boas condições para que egressos do curso possam trabalhar temas relacionados ao meio ambiente em sala de aula. Pois durante o processo formativo, os docentes do curso trabalham visando, além de outros objetivos, formar um cidadão ou cidadã que venha a contribuir na sociedade em que está inserido(a), por meio de ações conscientes que promovam a preservação do meio ambiente. $O$ egresso deve ser capaz de lidar racionalmente com a complexa e crescente necessidade de promover consciência ambiental.

Os autores desta pesquisa esperam contribuir para a adoção de políticas internas no CLCN, no sentido de melhorar cada vez mais a qualidade da formação ofertada aos discentes do curso. Desta forma, este estudo levanta informações e possibilita refletir sobre o processo educativo voltado à EA de discentes do curso, além de proporcionar um olhar mais sensível aos temas que são de grande relevância para a região.

Agradecimentos: Ao Campus Universitário do Marajó-Breves, pelo apoio financeiro à pesquisa; à Universidade Federal do Pará, por tornar possível o acesso as informações.

\section{Referências}

ABREU, D.G.; CAMPOS, M.L.A.M.; AGUILAR, M.B.R. Educação Ambiental nas escolas da região de Ribeirão Preto (SP): concepções orientadoras da prática docente e reflexões sobre a formação inicial de professores de química. Química Nova, v. 31, n. 3, p. 688-693, 2008. 
AUSUBEL, D.P.; NOVAK, J.D.; HANESIAN, H. (1978). Educational psychology: a cognitive view. 2nd. ed. New York, Holt Rinehart and Winston.

BRANQUINHO, N.C.S.S. Satisfação dos egressos do curso de graduação em enfermagem de uma universidade pública. (Dissertação). Programa de PósGraduação em Enfermagem, Universidade Federal de Goiás, Goiânia, GO, Brasil, 2012. Disponível em: <https://files.cercomp.ufg.br/weby/ up/127/o/Nayla Cec\%C3\%ADlia Silvestre da Silva Branquinho.pdf>.

BRASIL. Lei $\mathbf{N}^{\circ}$ 9.795, de 27 de abril de 1999. Disponível em: $<$ https://www.camara.leg.br/proposicoesWeb/prop mostrarintegra;jsessionid=5 0EE32BD99AF52EB7D5DB8E7E03AE765.node1 ?codteor $=634068$ \&ilename $=$ LegislacaoCitada+-PL+4692/2009>.

BRASIL. Lei $\mathbf{N}^{\circ}$ 12.305, de 2 de agosto de 2010, Presidência da República, Casa Civil, Subchefia para Assuntos Jurídicos. Disponível em: $<$ http://www.planalto.gov.br/ccivil 03/ ato2007-2010/2010/lei//12305.htm>.

BRASIL. RESOLUÇÃO № 2, de 1ำ de julho de 2015. Ministério da Educação, Conselho Nacional de Educação. Disponível em: <http://portal.mec.gov. br/docman/agosto-2017-pdf/70431-res-cne-cp-002-03072015-pdf/file>.

CAMARGO, S.C.G.; BRANCO, J.O. (2003). A Educação Ambiental na visão dos professores de ciências naturais, humanas e linguagem, Balneário Camboriú, SC. Anais do II Simpósio Sul Brasileiro de Educação Ambiental.

FLICK, U. Introdução à metodologia de pesquisa: um guia para iniciantes. Porto Alegre: Penso, 2013.

FREITAS, M.C.C., et al. Percepção socioambiental dos residentes do igarapé Santa Cruz no município de Breves-PA: vivências e desafios sobre a captação e uso da água. Revista Brasileira de Educação Ambiental, v. 15, n. 1, p. 328-350, 2020.

GIL, A.C. Métodos e técnicas de pesquisa social. São Paulo: Atlas. 2008.

LIMA, V. M. R.; SANTOS, M. Z. M. Processos de formação continuada: com a palavra o professor de ciências. Investigações em Ensino de Ciências, v. 22, n. 3, p. 61-79, 2017.

LOUSADA, A.C.Z.; MARTINS, G.A. Egressos como fonte de informação à gestão dos cursos de ciências contábeis. Revista Contabilidade e Finanças, São Paulo, USP, v. 16, n. 37, 2005.

MENDES, F.L.S.; SIMONIAN, L.T.L. (2016). Animais silvestres comercializados ilegalmente em algumas cidades do estado do Pará. Revista Eletrônica do Mestrado em Educação Ambiental, v. 33, n. 1, p. 4-21, 2016.

MORO, F. T.; DULLIUS, M. M. Formação continuada de professores nas Ciências da Natureza: uma análise das publicações em periódicos. Interfaces da Educação, v. 11, n. 33, 2020.

SILVA, M. M. P.; LEITE, V. D. Estratégias para realização de Educação Ambiental em escolas do ensino fundamental. Revista eletrônica do Mestrado em Educação Ambiental, v. 20, 2008. 